\title{
VDRL titres in early syphilis before and after
}

\section{treatment}

\author{
S Talwar, M A Tutakne, V D Tiwari
}

\begin{abstract}
Objective-To observe the pretreatment VDRL titres in different stages of early syphilis and evaluate the changes in VDRL titre following treatment using different treatment schedules.

Design-Retrospective study was carried out by analysing the records of cases of early syphilis treated between 1976 to 1981 . Setting-Armed Forces personnel treated at different service hospitals in India.

Subjects-Of 3183 cases of early syphilis treated with different regimens during this period, 1532 were fully followed-up for a period of 30 months. Records of these 1532 cases were analysed.
\end{abstract}

Main outcome measures-Assessment of VDRL titres before treatment and during post treatment surveillance period of $\mathbf{3 0}$ months. Attainment of non-reactivity of VDRL test in various stages of early syphilis using different treatment schedules was evaluated.

Results-Relatively higher titres were observed in secondary syphilis. Following treatment it was observed that VDRL test was still reactive at the end of 6 months in $16.47 \%$ of primary, $27.56 \%$ of secondary and $18.95 \%$ of early latent cases; at the end of 12 months in $11.38 \%$ of primary, $17 \cdot 25 \%$ of secondary and $15.79 \%$ of early latent cases while at 30 months reactivity was still observed in $6.60 \%$ of primary, $8 \cdot 39 \%$ of secondary and $11.58 \%$ of early latent cases. CSF was examined in 1173 cases at 6 months, of which one case revealed VDRL reactivity while two cases showed reactivity amongst 1188 CSF examined at 30 months. There has been no significant difference with broad spectrum antibiotics and $2.4 \mathrm{MU}$ benzathine penicillin. Results were better with 4.8 MU benzathine penicillin and procaine penicillin. Conclusion-VDRL test appears to be a reliable test for the follow-up of treated patients in early syphilis. Early treatment prevents development of seropositivity in seronegative syphilis while majority of seropositive cases attain seronegativity by 6 months. Higher doses of benzathine penicillin and procaine penicillin accelerate the speed of seroconversion.

\section{Introduction}

Tests for detecting antilipoidal antibodies, especially the VDRL test, are usually employed in clinical practice for detection and follow-up of syphilis. Antilipoidal antibodies usually appear 7-14 days after the beginning of primary stage, are always present in the secondary stage, but disappear during latency in about $30 \%$ of patients. ${ }^{1}$ They usually disappear after treatment if this is given within 2 years of infection, and therefore are best suited for the follow-up of treated patients. ${ }^{2}$ However, in conditions of high prevalence and limited resources VDRL test has been recommended for screening purpose as well. ${ }^{2}$ This study was undertaken to observe the serological response in early syphilis and to evaluate the changes in serology following treatment using VDRL test.

\section{Material}

Records of syphilis cases treated between January 1976 to July 1981 were analysed. As a routine these cases were placed on surveillance of 30 months after treatment. During surveillance serological tests for syphilis (VDRL) were done at 2 months intervals for the first six months followed by 3 months intervals for the next year, and lastly at 6 months intervals for the following year. The cerebrospinal fluid (CSF) was examined for cells, protein, globulin and VDRL test at the end of 6 and 30 months from the date of completion of treatment. Cases with a past history of syphilis were excluded from the study. Three thousand one hundred eighty three cases were treated during this period. Of these, 1532 cases were followed-up during the entire surveillance period. Frequent transfers of the individual, frequent moves of the unit where patient was serving, retirement/release from service, and refusal to undergo surveillance are some of the important reasons for cases being lost to follow-up during long surveillance of 30 months. Records of these 1532 cases were analysed. The various treatment schedules used were: (a) 2.4 MU benzathine penicillin (schedule A), (b) $4.8 \mathrm{MU}$ benzathine pencillin given in two divided doses at 1 week interval (schedule D), (c) procaine penicillin given as $0.6 \mathrm{MU}$ per day for 10 days (schedule $\mathrm{C}$ ), (d) broad spectrum antibiotics; tetracycline, chloromycetin and erythromycin were used in doses of $2 \mathrm{~g}$ per day and ledermycin in doses of $1200 \mathrm{mg}$ per day for 15 days (schedule B).

\section{Results}

Of 1532 followed-up cases 1008 were diagnosed as primary, 429 as secondary and 95 as latent syphilis (less than 2 years duration). 
Benzathine penicillin ( $2 \cdot 4 \mathrm{MU})$ was used in 1323 cases $(86.36 \%) ; 4.8 \mathrm{MU}$ in 34 cases of seconday syphilis and 19 cases of latent syphilis; procaine penicillin was used in 17 cases and broad spectrum antibiotics were used in 139 cases who were allergic to penicillin (from history/skin testing). In the majority of the cases the pretreatment VDRL titre was between 16-32 dilutions (table 1). In secondary syphilis higher titres were observed; how-

Table 1 Analysis of pretreatment serological titres using VDRL test in early syphilis

\begin{tabular}{|c|c|c|c|c|}
\hline \multirow[b]{2}{*}{ Diagnosis } & \multicolumn{4}{|c|}{ Pretreatment VDRL Titres (dilutions) } \\
\hline & $1-8$ & $16-12$ & 64 and above & Total \\
\hline & $\begin{array}{l}341 \\
(36.94 \%)\end{array}$ & $\begin{array}{l}503 \\
(54 \cdot 50 \%)\end{array}$ & 79 & 923* \\
\hline Secondary & $\begin{array}{l}95 \\
(22 \cdot 14 \%)\end{array}$ & $\begin{array}{l}263 \\
(61.31 \%)\end{array}$ & 71 & 429 \\
\hline Latent & $\begin{array}{l}43 \\
(45 \cdot 26 \%)\end{array}$ & $\begin{array}{l}49 \\
(51.58 \%)\end{array}$ & $\begin{array}{l}3 \\
(3 \cdot 16 \%)\end{array}$ & 95 \\
\hline
\end{tabular}

*Excluding 85 seronegative cases.

Table 2 Post treatment serology (VDRL) during surveillance in seronegative primary syphilis

\begin{tabular}{|c|c|c|c|c|c|c|}
\hline \multirow{3}{*}{$\begin{array}{l}\text { Treatment } \\
\text { schedule }\end{array}$} & \multicolumn{6}{|c|}{ Serology on follow-up (months) } \\
\hline & \multicolumn{2}{|l|}{6 months } & \multicolumn{2}{|l|}{12 months } & \multicolumn{2}{|l|}{30 months } \\
\hline & No. done & No. reactive & No. done & No. reactive & No. done & Na. reactive \\
\hline $\begin{array}{l}\text { A } \\
\text { B } \\
\text { Total }\end{array}$ & $\begin{array}{r}78 \\
7 \\
85\end{array}$ & $\begin{array}{l}1(1 \cdot 28 \%) \\
\overline{1}(1 \cdot 28 \%)\end{array}$ & $\begin{array}{r}78 \\
7 \\
85\end{array}$ & $\begin{array}{l}- \\
-\end{array}$ & $\begin{array}{r}78 \\
7 \\
85\end{array}$ & $\begin{array}{l}- \\
-\end{array}$ \\
\hline
\end{tabular}

Table 3 Post treatment serology (VDRL) during surveillance in seropositive primary syphilis

\begin{tabular}{|c|c|c|c|c|c|c|}
\hline \multirow{3}{*}{$\begin{array}{l}\text { Treatment } \\
\text { schedule }\end{array}$} & \multicolumn{6}{|c|}{ Serology on follow-up (months) } \\
\hline & \multicolumn{2}{|l|}{6 months } & \multicolumn{2}{|l|}{12 months } & \multicolumn{2}{|l|}{30 months } \\
\hline & No. done & No. reactive & Na. done & No. reactive & No. done & No. reactive \\
\hline $\begin{array}{l}\text { A } \\
\text { B } \\
\text { C } \\
\text { Total }\end{array}$ & $\begin{array}{r}836 \\
81 \\
6 \\
923\end{array}$ & $\begin{array}{r}139(16.63 \%) \\
13(16.05 \%) \\
-\quad \\
152(16.47 \%)\end{array}$ & $\begin{array}{r}836 \\
81 \\
6 \\
923\end{array}$ & $\begin{array}{c}97(11.60 \%) \\
8(9.88 \%) \\
-\quad \\
105(11.38 \%)\end{array}$ & $\begin{array}{r}836 \\
81 \\
6 \\
923\end{array}$ & $\begin{array}{r}55(6.58 \%) \\
6(7.41 \%) \\
-\quad \\
61(6.60 \%)\end{array}$ \\
\hline
\end{tabular}

Table 4 Post treatment serology (VDRL) during surveillance in secondary syphilis

\begin{tabular}{|c|c|c|c|c|c|c|}
\hline \multirow{3}{*}{$\begin{array}{l}\text { Treatment } \\
\text { schedule }\end{array}$} & \multicolumn{6}{|c|}{ Serology on follow-up (months) } \\
\hline & \multicolumn{2}{|l|}{6 months } & \multicolumn{2}{|l|}{12 months } & \multicolumn{2}{|l|}{30 months } \\
\hline & No. done & No. reactive & No. done & No. reactive & No. done & No. reactive \\
\hline $\begin{array}{l}\text { A } \\
\text { D } \\
\text { C } \\
\text { B } \\
\text { Total }\end{array}$ & $\begin{array}{r}343 \\
34 \\
11 \\
41 \\
429\end{array}$ & $\begin{array}{r}97(28 \cdot 28 \%) \\
7(20 \cdot 59 \%) \\
3(27 \cdot 27 \%) \\
11(26 \cdot 83 \%) \\
118(27 \cdot 50 \%)\end{array}$ & $\begin{array}{r}343 \\
34 \\
11 \\
41 \\
429\end{array}$ & $\begin{array}{r}67(19 \cdot 53 \%) \\
2(5 \cdot 88 \%) \\
-\quad \\
5(12 \cdot 16 \%) \\
74(17 \cdot 25 \%)\end{array}$ & $\begin{array}{r}343 \\
34 \\
11 \\
41 \\
429\end{array}$ & $\begin{array}{r}30(8.75 \%) \\
2(5.88 \%) \\
-\quad \\
4(9 \cdot 76 \%) \\
36(8.39 \%)\end{array}$ \\
\hline
\end{tabular}

Table 5 Post treatment serology (VDRL) during surveillance in early latent syphilis

\begin{tabular}{|c|c|c|c|c|c|c|}
\hline \multirow{3}{*}{$\begin{array}{l}\text { Treatment } \\
\text { schedule }\end{array}$} & \multicolumn{6}{|c|}{ Serology on follow-up (months) } \\
\hline & \multicolumn{2}{|l|}{6 months } & \multicolumn{2}{|l|}{12 months } & \multicolumn{2}{|l|}{30 months } \\
\hline & No. done & No. reactive & No. done & No. reactive & No. done & No. reactive \\
\hline $\begin{array}{l}\text { A } \\
\text { D } \\
\text { B } \\
\text { Total }\end{array}$ & $\begin{array}{l}66 \\
19 \\
10 \\
95\end{array}$ & $\begin{array}{c}14(21 \cdot 12 \%) \\
3(15 \cdot 79 \%) \\
1(10 \%) \\
18(18.95 \%)\end{array}$ & $\begin{array}{l}66 \\
19 \\
10 \\
95\end{array}$ & $\begin{aligned} & 12(18 \cdot 18 \%) \\
& 2(10 \cdot 53 \%) \\
& 1(10 \%) \\
& 15(15 \cdot 79 \%)\end{aligned}$ & $\begin{array}{l}66 \\
19 \\
10 \\
95\end{array}$ & $\begin{array}{l}10(15 \cdot 15 \%) \\
\frac{1}{1}(10 \%) \\
11(11 \cdot 58 \%)\end{array}$ \\
\hline
\end{tabular}

ever, very high titres (64 and above) were observed in only $16.55 \%$. Latent syphilis had relatively low titre. Pretreatment VDRL titres as observed in seropositive primary syphilis had no relation to duration of symptoms. The maximum duration of symptoms giving VDRL negativity in primary syphilis was 27 days while the minimum duration of symptoms giving VDRL positivity in primary syphilis was 2 days. In 85 cases of seronegative primary syphilis (diagnosed on the basis of demonstration of $T$ pallidum by dark field microscopy), VDRL test repeated at 6 months revealed reactivity in one case (table 2 ). In this particular case seropositivity was detected within the first two months of treatment when the patient reported for first follow-up and had persisted for 6 months in decreasing titres. However, no case showed reactivity at the end of 12 months and among 85 cases who completed surveillance there was no treatment failure. VDRL was still reactive at the end of 6 months in $16.47 \%$ of primary, $27.56 \%$ of secondary and $18.95 \%$ of early latent cases; at the end of 12 months in $11.38 \%$ of primary, $17 \cdot 25 \%$ of secondary and $15 \cdot 79 \%$ of early latent cases while at $\mathbf{3 0}$ months reactivity was still observed in $6.60 \%$ of primary, $8.39 \%$ of secondary and $11.58 \%$ of early latent cases (tables 3-5). CSF was examined in 1173 cases at 6 months, of which one sample showed abnormality including VDRL reactivity while at 30 months three samples were abnormal out of 1188 examined. VDRL reactivity was seen in two of these cases and one case showed VDRL nonreactivity but had increased number of cells, protein and globulin.

\section{Discussion}

VDRL titres reach their maximum level rapidly, often within 1 or 2 weeks. ${ }^{34}$ Accordingly some of the cases reporting as early as 2 days of illness revealed high titres while some of the cases reporting as late as more than $\mathbf{3 0}$ days of illness revealed low titres.

Generally following treatment seronegativity is achieved in 12 months in primary syphilis ${ }^{5}$ and 24 months in secondary syphilis. Serological trends seen in the present study compare well with the previous studies. ${ }^{5-7}$ Results are better in primary as compared to secondary and results in secondary are better than latent cases. Serology becoming positive for a short period in seronegative cases does not indicate a treatment failure. The rapidity of the antibody response varies directly with the number of treponemes innoculated. ${ }^{4}$ Accordingly some of the seronegative cases where antigenic recognition has taken place following infection but reaginic antibody production has not commenced, may show seronegative state initially but later convert to seropositive state even after treatment. It is believed that following treatment $90-95 \%$ of seronegative primary syphilis may remain seronegative while 5-10\% may become seropositive. ${ }^{3}$ All the cases of seronegative primary syphilis were declared as cured after the surveillance period. This confirms the view that the earlier the treatment is 
given the better are the results and early treatment may also prevent the development of a seropositive stage; while if treatment is delayed, the greater are the chances of persistance of seroreactivity. ${ }^{8}$ Secondary syphilis had a high initial titre, so more cases were found to be reactive at 6 months and 12 months as compared with primary and latent cases with relatively low initial titres. This supports the view that serological response following treatment correlates with an initial serological titre. ${ }^{9}$ There was no case of seronegative secondary syphilis, although some cases have been reported. ${ }^{11}$ In latent syphilis relative low initial titres were seen but following treatment seroreactivity persisted in a maximum number of cases at 30 months $(11.58 \%)$. Accordingly in latent syphilis a satisfactory response in serology is considered to be (a) four fold or greater decrease in titre of the reagin test during the first year after treatment and (b) conversion of the reagin test to seronegativity within 4 years after treatment. Initial attainment of VDRL negativity following treatment is rapid in all stages and by 6 months $82 \cdot 14 \%$ become seronegative. Thereafter sero-conversion is slow, being slowest in latent syphilis. Overall $7 \cdot 05 \%$ of cases still showed reactivity at 30 months. One should not attempt retreatment to achieve seronegativity in these cases. Depending on serology retreatment is recommended ${ }^{12}$ if (a) there is sustained four fold rise in titre of non-treponemal serological test, (b) an initially high titre, non-treponemal (1:8 or above) persists for a year. Quantitative non-treponemal serological test done at 3,6 and 12 months after treatment is considered satisfactory. ${ }^{13}$ Relatively slow seroconversion observed after 6 months in the present series supports the WHO recommendations of relatively shorter follow-up. Higher doses of benzathine penicillin $(4 \cdot 8$ $\mathrm{MU}$ ) used in some cases of secondary and latent syphilis revealed better response, as has also been observed by others. ${ }^{914}$ Procaine penicillin used in 17 cases resulted in VDRL negativity in all cases. However, the number of cases treated is too small to draw any conclusion. Trial in large series will futher help in its proper evaluation. Response with broad spectrum antibiotics and $2 \cdot 4 \mathrm{MU}$ benzathine penicillin has been nearly identical.

In all the four cases with abnormal CSF, the blood VDRL test has also remained reactive although one case revealed negative serology in CSF with VDRL test. VDRL test in CSF is regarded as a less reliable indicator in the detection of neurosyphilis. ${ }^{15} 16$

1 Diggory P. Role of VDRL test in detection of syphilis. $\mathrm{Br} \mathcal{Y}$ Venereal Dis 1983;59:8-10.

WHO Report of Scientific Group on Treponemal Infection, Tech Rep Ser No 674, Geneva, WHO, 1982;30.

3 Moore JE, Mohr CF. Biologically false positive serological tests of syphilis. Type, incidence and cause. $\mathfrak{F} A M A$ 1952;150:467-73.

4 Kent JF. Course of the serological reaction in rabbits inoculated with different numbers of Treponema pallidum. Am $\mathcal{F}$ Clin Pathol 1964;42:33-6.

5 Schroeter AL Lucas JB. Treatment of early syphilis and reactivity of serological tests. $\mathcal{F} A M A$ 1972;221:471-6.

6 Willcox RR. Treatment of early venereal syphilis with

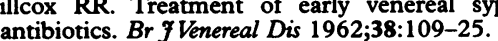

7 Anderson J, Mindel A, Tovey SJ, Williams P. Primary and secondary syphilis, 20 year's experience, 3: Diagnosis, secondary syphilis, 20 year's experience, 3: Diagnosis, 65:239-43.

8 Jefferiss FJG. Willcox RR. Treatment of early syphilis with penicillin alone. Br $\mathcal{F}$ Venereal Dis 1963;39:143-8.

9 Fuimara NJ. Treatment of primary and secondary syphilis serological response. $\mathscr{F} A M A$ 1980;243:2500-2.

10 Dutta RK, Malik AK. An unusual case of seronegative secondary syphilis. Indian $\mathcal{f}$ Dermatol Venereol Leprol. $1983 ; 28: 81-4$.

11 Masawe AEJ, Lomholt G, Aho $K$, Lassus A. Unusual behaviour of serological tests for syphilis in Ugandian Africans. Br Y Venereal Dis 1972;48:345-9.

12 WHO Report of Expert Committee on Venereal Disease and Treponematosis-Sixth report, Tech Rep Ser No 736, Treponematosis-Sixth report

13 Centres for Disease Control. Syphilis-CDC recommended treatment schedules, MMWR 1976;25:101-2.

14 Durst RD. Dose related seroreversal in syphilis. Arch Dermatol 1973;100:663-4.

15 Escobar MR. Fluorescent antibody test for syphilis using cerebrospinal fluid. Am $\mathcal{~}$ Clin Pathol 1970;53:886-90.

16 Lukehart SA, Hoow EW, Zander SAB, Collier AC, Critchlow CW. Invasion of the central nervous system by Treponema Pallidum: Implications for diagnosis and treatment. Ann Int Med 1988;109:855-61. 